
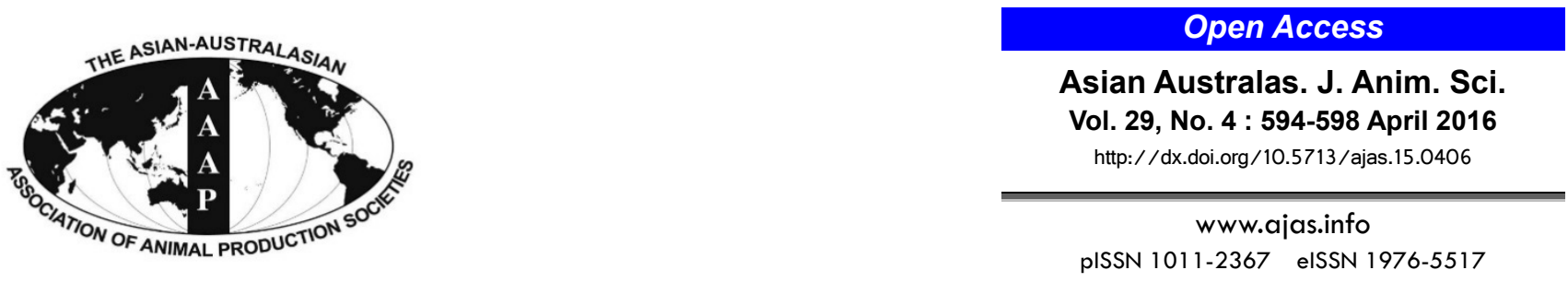

\title{
Characterization of Odorant Compounds from Mechanical Aerated Pile Composting and Static Aerated Pile Composting
}

\author{
Priyanka Kumari ${ }^{1}$, Joonhee Lee ${ }^{1}$, and Hong-Lim Choi ${ }^{1,2, *}$ \\ ${ }^{1}$ Department of Agricultural Biotechnology, Research Institute for Agriculture and Life Science, \\ Seoul National University, Seoul 151-921, Korea
}

\begin{abstract}
We studied airborne contaminants (airborne particulates and odorous compounds) emitted from compost facilities in South Korea. There are primarily two different types of composting systems operating in Korean farms, namely mechanical aerated pile composting (MAPC) and aerated static pile composting (SAPC). In this study, we analyzed various particulate matters (PM10, PM7, PM2.5, PM1, and total suspended particles), volatile organic compounds and ammonia, and correlated these airborne contaminants with microclimatic parameters, i.e., temperature and relative humidity. Most of the analyzed airborne particulates (PM7, PM2.5, and PM1) were detected in high concentration at SAPC facilities compered to MAPC; however these differences were statistically non-significant. Similarly, most of the odorants did not vary significantly between MAPC and SAPC facilities, except for dimethyl sulfide (DMS) and skatole. DMS concentrations were significantly higher in MAPC facilities, whereas skatole concentrations were significantly higher in SAPC facilities. The microclimate variables also did not vary significantly between MAPC and SAPC facilities, and did not correlate significantly with most of the airborne particles and odorous compounds, suggesting that microclimate variables did not influence their emission from compost facilities. These findings provide insight into the airborne contaminants that are emitted from compost facilities and the two different types of composting agitation systems. (Key Words: Ammonia, Compost, Manure, Microclimate Variables, Odorant, Volatile Organic Compounds)
\end{abstract}

\section{INTRODUCTION}

Composting is a naturally occurring biochemical process utilizing controlled aerobic decomposition of organic material. The product of composting is a moist, crumbly, soil-like product with a tolerable, earthy odor that is used as a natural fertilizer and soil conditioner for agricultural land. Compost is widely considered to be a low-cost and environmentally friendly method of managing and treating solid organic waste. There are several advantages of compost when used in adequate amounts and with proper management, which includes providing a wide range of nutrients to soils, increasing soil organic content,

\footnotetext{
* Corresponding Author: Hong-Lim Choi. Tel: +82-2-880-4808, Fax: +82-2-874-4808, E-mail: ulsoo8@snu.ac.kr

${ }^{2}$ Resourcification Research Center for Crop-Animal Farming (ReCAF), College of Agriculture and Life Sciences, Seoul National University, Seoul 151-921, Korea.

Submitted May 7, 2015; Revised Jun. 15, 2015; Accepted Jul. 6, 2015
}

improving water holding capacity and other physical properties of soil (Wells et al., 2000). In addition, compost application benefits essential soil organisms and reduces plant pathogens, which facilitates improved growth and higher yields of a variety of crop plants (D'Hose et al., 2012).

However, compost facilities that contain feedstock's or compost piles that are not well maintained may emit substantial and offensive odors (Tsai et al., 2008). In such circumstances, composting may be producing and releasing volatile organic compounds (VOCs) and ammonia due to intense microbial activity (Hellebrand, 1998). VOCs are organic compounds that melt at temperatures lower than room temperature and have boiling points between $50^{\circ} \mathrm{C}$ to $260^{\circ} \mathrm{C}$ (World Health Organization, 1989). VOCs include nitrogen-based compounds, sulfur-based compounds, volatile fatty acids, hydrocarbons, trepans, esters, ethers, alcohols, and aldehydes/ketones (Smet et al., 1999). The VOCs generated by composting can be evaluated in terms 
of two processes: the production within the pile due to degradation of organic matter and emission from the pile surface following gas convection within the pile. In several previous studies, it was found that most VOCs were emitted in the former (i.e., degradation of organic matter) phase of composting than in the latter (i.e., surface emission) phase (Eitzer, 1995; Turan et al., 2007; Kumar et al., 2011).

In South Korea, approximately 46.5 million tons of animal manure are produced annually and approximately $87 \%$ of this is applied to farm lands as compost and liquid organic fertilizer (Ahn et al., 2011). Two types of composting systems are primarily used on Korean farms, namely mechanical aerated pile composting (MAPC) and aerated static pile composting (SAPC). However, there is at present no research that characterizes the entire range of odorants and their correlation to microclimate variables in these systems. Therefore, the objective of the present study is to identify the various odorants emitted from these composting facilities and to correlate the microclimatic variables with the emitted odorants according to type of composting system.

\section{MATERIALS AND METHODS}

Experimental site description, sample collection and analysis of microclimatic variables

Ten compost facilities located within South Korea were chosen for sampling, depending on the type of composting system used, i.e., SAPC and MAPC; details about the composting systems are presented in Table 1. Most of the manure used in each of the ten compost facilities originated from the farm itself. Duplicate experiments were carried out on newly formed compost windrows (36 days old) between September and October of 2012, respectively. Strongly emitting or 'hot' locations in the sources were not sought out. We used environmental flux chambers to collect the emissions from the tipping pile or compost windrows at each of the compost facilities. The collected emissions were analyzed in the laboratory for VOC composition and

Table 1. Summary of visited compost facilities

\begin{tabular}{lcccc}
\hline Farm & Size (tons/d) & Mixing & Technology & Feedstock \\
\hline FM 1 & 60 & Mechanical & APC & CM \\
FM 2 & 50 & Mechanical & APC & CM \\
FM 3 & 74 & Mechanical & APC & CM \\
FM 4 & 66 & Mechanical & APC & CM \\
FM 5 & 8 & Mechanical & APC & CM \\
FM 6 & 20 & Static & SAPC & CM \\
FM 7 & 35 & Static & SAPC & CM \\
FM 8 & 16 & Static & SAPC & CM \\
FM 9 & 2.4 & Static & SAPC & CM \\
FM 10 & 18 & Static & SAPC & CM \\
\hline
\end{tabular}

APC, aerated pile composting (APC); SAPC, aerated static pile composting; CM, cattle manure and bedding material. ammonia. A hygrothermograph was used to measure air temperature and relative humidity (SK-110TRH, SATO, Tokyo, Japan).

\section{Analysis of airborne particulates and odorants}

Particulate matter (PM) was analyzed using an aerosol mass monitor (GT-331, SIBATA, Soca-city, Japan) and the mass concentrations of $\mathrm{PM}_{10}$ (PM average aerodynamic diameter: $10 \mu \mathrm{m}), \mathrm{PM}_{7}$ (PM average aerodynamic diameter: $7 \mu \mathrm{m}), \mathrm{PM}_{2.5}$ (PM mean aerodynamic diameter: $\left.2.5 \mu \mathrm{m}\right)$, $\mathrm{PM}_{1}$ (PM mean aerodynamic diameter: $1 \mu \mathrm{m}$ ), and total suspended particles were obtained simultaneously, with a flow rate of $2.83 \mathrm{~L} / \mathrm{min}$.

A low-volume air sampler was used to collect the samples for ammonia analysis (No. 800510, Gilian, Clearwater, FL, USA) at a speed of $2 \mathrm{~L} / \mathrm{min}$ for $3 \mathrm{~min}$, absorbed by $0.5 \%$ boric acid. An indophenols method, based on the appearance of an indophenol blue pigment that forms when phenol reacts with hypochlorite in the presence of ammonia (Weatherburn, 1967; Lewandowska and Falkowska, 2004), was used to determine ammonia concentrations. The detection limit for ammonia using this method is $0.44 \mathrm{mg} / \mathrm{L}$. A total of 11 different types of VOCs were analyzed in this study, which included two sulfuric compounds (dimethyl sulfide [DMS] and dimethyl disulfide [DMDS]); six volatile fatty acids (acetic acid, propionic acid, butyric acid, iso-butyric acid, valeric acid and isovaleric acid); two indolics (indole and skatole); and one phenolic ( $\mathrm{p}$-cresol). The air was sampled for 5 min using a 1 L Tedlar bag (No.22053, Restek, Bellefonte, PA, USA). The collected air samples were analyzed using gas chromatography/mass spectrometry (GC/MS) (Agilent GC6890N/5975C MS, Youngin, Korea) in the laboratory, and all samples were analyzed within 4 hours of sample collection. Solid-phase microextraction (SPME) fibers (Solid Phase Microextraction Fiber, Supelco, Bellefonte, PA, USA) consisting of 75-mm carboxen-polydimethylsiloxane were used for the analysis. Samples were extracted by using SPME fibers for $10 \mathrm{~min}$ with a manual fiber holder from Supelco (USA). Following extraction, the SPME fiber was removed from the Tedlar bag and immediately inserted into the injection port of the GC/MS for analysis. The reabsorption time of a SPME fiber was $5 \mathrm{~min}$ at $250^{\circ} \mathrm{C}$ with a $0.75 \mathrm{~mm}$ injection port liner. The temperature program used was as follows: $35^{\circ} \mathrm{C}$ initial, 5 -min hold; $6^{\circ} \mathrm{C} \mathrm{min} / \mathrm{L}$ to $140^{\circ} \mathrm{C}, 0$-min hold; $15^{\circ} \mathrm{C} \mathrm{min} / \mathrm{L}$ to $220^{\circ} \mathrm{C}, 3$-min hold. The concentrations were calculated as the parts per billion (ppb, $\mathrm{nmol} \mathrm{mol} / \mathrm{L}$ ) and milligram per cubic meter.

\section{Standards and calibration}

For DMS and DMDS, a mixed standard gas (10.4 ppm DMS and 9.9 ppm DMDS, Research Institute of Gas Analytical Science, South Korea) was used for the 
quantification. For other compounds, the calibrations were accomplished through the use of the headspace method for Henry's constants (Chai et al., 2005). All of the reagents were purchased from Sigma-Aldrich (St. Louis, MO, USA): acetic acid (99.7\%), propanoic acid (99.5\%), bButyric acid $(99 \%)$, isobutyric acid $(99 \%)$, valeric acid (99\%), isovaleric acid (99\%), indole (99\%), skatole (98\%) and p-cresol (99\%). The stocking solutions of volatile organic acids were diluted with triple-distilled water, while the stocking solutions of the Indolics and p-cresol were diluted with methanol (99.9\%, Sigma-Aldrich, USA). The stocking solutions were diluted progressively with triple-distilled water and analyzed with a relative headspace method for Henry's constants (Chai et al., 2005). The detection thresholds, molecular weights and retention times of the target odorous compounds are shown in Table 2. Recovery of these VOCs in Tedlar bags was greater than $85 \%$ under similar experimental conditions.

\section{Statistical analysis}

Statistical evaluations were carried out using an SPSS software package (SPSS Inc., Chicago, IL, USA). Comparisons of each variable across different farms were first performed with standard t-tests of equality of means at a 5\% significance level. For multiple comparisons between means of a factor, we used Bonferroni corrections with an $\alpha$-value of 0.05 . Pairwise correlations (Kendall's $\tau$-b correlation coefficients) were calculated among the different factors, such as microclimate variables, PM, VOCs, and odorous compounds.

\section{RESULTS AND DISCUSSION}

\section{Microclimate variables in the compost facilities}

Means of microclimate variables in compost facilities are presented in Table 3 . The mean values of temperature in the different compost plants across the two agitation systems were $30.5^{\circ} \mathrm{C}$ and $28^{\circ} \mathrm{C}$ for MAPC and SAPC, respectively (Table 3 ). However, the mean values of relative
Table 3. Means of the microclimate variables in MAPC and SAPC systems

\begin{tabular}{lcc}
\hline $\begin{array}{l}\text { Agitation } \\
\text { system }\end{array}$ & Temperature $\left({ }^{\circ} \mathrm{C}\right)$ & Relative humidity (\%) \\
\hline MAPC & $30.5 \pm 4.9$ & $66.3 \pm 28.0$ \\
SAPC & $28.0 \pm 2.8$ & $52.8 \pm 19.7$ \\
p-value & 0.359 & 0.405 \\
\hline $\begin{array}{l}\text { MAPC, mechanical aerated pile composting; SAPC, aerated static pile } \\
\text { composting. }\end{array}$
\end{tabular}

humidity were $66.3 \%$ and $52.8 \%$ for MAPC and SAPC, respectively (Table 3 ). The microclimate variables did not vary significantly between MAPC and SAPC (all p>0.05). Because of the high temperature, farm managers maximized ventilation in order to increase the convection heat loss of the compost facilities in all types of farms.

\section{Particulate matter and odorous compounds in composting facilities}

Mean values of airborne particulates and odorous compounds in the composting facilities is shown in Table 4. The concentrations of most of the airborne particulates (PM7, PM2.5, and PM1) were high in SAPC facilities compared to MAPC, however these differences were nonsignificant (Table 4). Similarly, most of the analyzed VOCs concentrations were not varied significantly between MAPC and SAPC facilities (Table 4), except for DMS and skatole concentrations (Table 4), with the DMS concentration being significantly higher in MAPC and the skatole concentration being significantly higher in SAPC. Several previous studies have shown DMS to be one of the typical sulphur compounds emitted during the composting process (Krauss et al., 1992; Smet et al., 1999). The concentration of ammonia was higher in MAPC compared to SAPC, however this difference was statistically nonsignificant. For ammonia, the threshold limit value of the time-weighted average is $25 \mathrm{mg} / \mathrm{L}$ (ACGIH, 2013). In this study, the ammonia concentrations in MAPC and SAPC facilities were ranged from $81.7 \mathrm{mg} / \mathrm{L}$ to $420 \mathrm{mg} / \mathrm{L}$ and 4

Table 2. Summary of volatile organic compounds (VOCs) quantified in the study using gas chromatography/mass spectrometry

\begin{tabular}{llccc}
\hline Group & Compound & Molecular weight & Retention time (min) & Detection threshold \\
\hline Phenolic compound (ppbv) & P-Cresol & 94.1 & 20.2 & 2.90 \\
Indolics compounds (ppbv) & Indole & 117.1 & 25.2 & 1.36 \\
& Skatole & 131.1 & 25.6 & 0.13 \\
Sulphur compounds (ppbv) & Dimethyl disulfide (DMS) & 94.2 & 5.2 & 0.11 \\
& Dimethyl trisulfide (DMDS) & 126.2 & 11.0 & 0.26 \\
Volatile fatty acids (ppbv) & Acetic acid (AA) & 60.0 & 12.4 & 9.33 \\
& Propanoic acid (PA) & 74.1 & 13.8 & 0.009 \\
& Isobutyric acid (I-BA) & 88.1 & 14.2 & 1.27 \\
& Butyric acid (BA) & 88.1 & 15.1 & 0.10 \\
& Isovaleric acid (I-VA) & 102.1 & 15.7 & 3.17 \\
& Valeric acid (VA) & 102.1 & 16.7 & 0.48 \\
\hline
\end{tabular}


Table 4. Airborne particulates and odorants detected in MSAPC and SAPC

\begin{tabular}{lcl}
\hline & MAPC & SAPC \\
\hline Odorant & & \\
DMS* & $0.96 \pm 0.5$ & $0.45 \pm 0.17$ \\
DMDS & $0.24 \pm 0.3$ & $0.11 \pm 0.07$ \\
AA & $36.3 \pm 25.8$ & $46.5 \pm 22.3$ \\
PA & $48.4 \pm 65.7$ & $70.4 \pm 30.5$ \\
BA & $16.5 \pm 0.2$ & $17.7 \pm 2.1$ \\
I-BA & $31.1 \pm 1.1$ & $34.5 \pm 7$ \\
VA & $29.1 \pm 0.1$ & $29.4 \pm 0.65$ \\
I-VA & $26.6 \pm 0.2$ & $26.5 \pm 0.04$ \\
P-Cresol & $1.7 \pm 0.8$ & $1.7 \pm 0.9$ \\
Indol & $72.3 \pm 99.1$ & $7.9 \pm 16.1$ \\
Skatole* & $0.78 \pm 0.54$ & $4.2 \pm 3$ \\
NH$_{3}$ & $211.9 \pm 143$ & $85.4 \pm 72.7$ \\
Particulate matter (PM) & & \\
PM $_{10}$ & $79.3 \pm 81.01$ & $76.5 \pm 36.1$ \\
PM $_{7}$ & $28 \pm 19.8$ & $66.6 \pm 38.1$ \\
PM $_{2.5}$ & $11.4 \pm 13.9$ & $41.1 \pm 32.8$ \\
PM $_{1}$ & $4.7 \pm 7.8$ & $14.1 \pm 9$ \\
TSP $^{*}$ & $150.7 \pm 227.2$ & $83.7 \pm 34.4$ \\
\hline
\end{tabular}

MAPC, mechanical aerated pile composting; SAPC, aerated static pile composting; DMS, dimethyl sulfide; DMDS, dimethyl disulfide; AA, acetic acid; PA, propanoic acid; BA, butyric acid; I-BA, isobutyric acid; VA, valeric acid; I-VA, isovaleric acid; TSP, total suspended particles. $* \mathrm{p}<0.05$.

$\mathrm{mg} / \mathrm{L}$ to $191.7 \mathrm{mg} / \mathrm{L}$, respectively. On an average, in both MAPC and SAPC facilities ammonia concentration was higher than the threshold limit value, a finding that is in accordance with several previous studies (Radon et al., 2002; Hayes et al., 2006).

Correlations between microclimate variables and airborne particles and odorants

Kendall's $\tau$-b correlation coefficients of microclimate variables and PM are presented in Table 5. All of the significant correlations between airborne particulates and
Table 5. Kendall's correlation coefficients for microclimate variables with particulate matter $(\mathrm{PM})$

\begin{tabular}{|c|c|c|c|c|c|}
\hline \multirow{2}{*}{ Kendall's } & \multicolumn{5}{|c|}{$\mathrm{PM}$} \\
\hline & $\mathrm{PM}_{10}$ & $\mathrm{PM}_{7}$ & $\mathrm{PM}_{2.5}$ & $\mathrm{PM}_{1}$ & TSP \\
\hline \multicolumn{6}{|c|}{ Temperature $\left({ }^{\circ} \mathrm{C}\right)$} \\
\hline MAPC & -0.40 & $-0.80 * *$ & $-0.60 *$ & -0.40 & -0.40 \\
\hline SAPC & -0.44 & -0.48 & $-0.60 *$ & $-0.67 *$ & -0.38 \\
\hline Total & -0.15 & -0.42 & -0.42 & -0.44 & -0.09 \\
\hline \multicolumn{6}{|c|}{ Relative humidity (\%) } \\
\hline MAPC & -0.20 & 0.20 & 0.00 & -0.20 & -0.20 \\
\hline SAPC & 0.55 & 0.59 & $0.70^{*}$ & $0.76^{* *}$ & 0.49 \\
\hline Total & -0.20 & 0.06 & 0.06 & 0.09 & -0.27 \\
\hline
\end{tabular}

temperature were negative (Table 5), whereas all of the significant correlations between airborne particulates and relative humidity were positive (Table 5). When temperature was correlated to odorants concentration, most of the correlation values were negative but non-significant (Table 6), except for VS, which was significantly negatively correlated with temperature (Table 6). Similarly, there was no significant correlation between most of the odorants and relative humidity (Table 6), with the exception of DMDS and p-cresol, the concentrations of which were positively correlated with relative humidity (Table 6). These results suggest that microclimate variables (temperature and relative humidity) are not the major determinants of the emission of odorous compounds from the compost facilities.

In conclusion, the microclimate variables studied here (temperature and relative humidity) did not vary between the two different types of composting agitation systems (MAPC and SAPC). Most of the airborne particles concentration was higher in SAPC compared to MAPC, though these differences were statistically non-significant. Similarly, the concentrations of most of the odorous compounds did not vary significantly in both types of composting agitation systems, except for DMS and skatole,

Table 6. Kendall's correlation coefficients for microclimate variables with odorants

\begin{tabular}{|c|c|c|c|c|c|c|c|c|c|c|c|c|}
\hline \multirow{2}{*}{ Kendall's } & \multicolumn{12}{|c|}{ Odorant } \\
\hline & DMS & DMDS & AA & PA & BA & I-BA & VA & IVA & P-Cresol & Indole & Skatole & $\mathrm{NH}_{3}$ \\
\hline \multicolumn{13}{|c|}{ Temperature } \\
\hline MAPC & 0.00 & -0.20 & -0.20 & 0.00 & -0.10 & 0.00 & $-0.60 *$ & -0.20 & -0.20 & 0.00 & -0.40 & 0.20 \\
\hline SAPC & -0.20 & -0.40 & -0.40 & 0.20 & 0.00 & 0.20 & -0.52 & -0.31 & 0.20 & 0.20 & 0.20 & 0.40 \\
\hline Total & 0.06 & -0.31 & -0.15 & -0.02 & -0.09 & 0.15 & -0.42 & -0.06 & -0.06 & 0.15 & -0.15 & 0.24 \\
\hline \multicolumn{13}{|c|}{ Relative humidity } \\
\hline MAPC & 0.20 & $0.80^{*}$ & -0.40 & -0.20 & -0.10 & -0.20 & 0.40 & 0.00 & $0.80 *$ & 0.20 & 0.60 & 0.40 \\
\hline SAPC & 0.20 & 0.40 & 0.40 & -0.20 & 0.00 & -0.20 & 0.52 & 0.31 & -0.20 & -0.20 & -0.20 & -0.04 \\
\hline Total & 0.20 & $0.62 *$ & -0.20 & -024 & -0.18 & -0.33 & 0.37 & 0.11 & 0.24 & 0.11 & -0.22 & 0.11 \\
\hline
\end{tabular}

DMS, dimethyl sulfide; DMDS, dimethyl disulfide; AA, acetic acid; PA, propanoic acid; BA, butyric acid; I-BA, isobutyric acid; VA, valeric acid; I-VA, isovaleric acid; MAPC, mechanical aerated pile composting; SAPC, aerated static pile composting.

$* \mathrm{p}<0.05$. 
with DMS concentrations higher in MAPC and skatole concentrations higher in SAPC. Furthermore, the microclimate variables were not significantly correlated with most of the airborne particles and odorous compounds, indicating that the microclimate variables did not influence their emission from the compost facilities. Overall, these findings provide an insight to the airborne contaminants emitted from two different type of composting agitation systems that dominate composting facilities in South Korea. To gain further understanding, there is a need for further more extensive sampling in both MAPC and SAPC facilities, at different times of year. Future research should also focus on strategies to reduce the emission of these airborne contaminants.

\section{CONFLICT OF INTEREST}

We certify that there is no conflict of interest with any financial organization regarding the material discussed in the manuscript.

\section{ACKNOWLEDGMENTS}

The authors acknowledge Hye-Jin Kang having helped in collecting data in the field. We are thankful to the Korea Institute of Planning and Evaluation for Technology in Food, Agriculture, Forestry, and Fisheries (IPET) from the Ministry of Agriculture, Food, and Rural Affairs (MAFRA) through project no. 312036-03-2-HD030, and in part by Korea Institute of Energy Technology Evaluation and Planning (KETEP) from the Ministry of Trade, Industry and Energy (MOTIE) through project no. 2012-3020090040 to support this work.

\section{REFERENCES}

ACGIH. 2013. TLVs and BEIs: Based on the documentation of the Threshold Limit Values for chemical substances and physical agents and Biological Exposure Indices. In: American Conference of Governmental Industrial Hygienists Cincinnati, $\mathrm{OH}$, USA.

Ahn, H. K., W. Mulbry, J. W. White, and S. L. Kondrad. 2011. Pile mixing increases greenhouse gas emissions during composting of dairy manure. Bioresour. Technol. 102:2904-2909.

Chai, X.-S., J. B. Falabella, and A. S. Teja. 2005. A relative headspace method for Henry's constants of volatile organic compounds. Fluid Phase Equilib. 231:239-245.
D'Hose, T., M. Cougnon, A. De Vliegher, E. Van Bockstaele, and D. Reheul. 2012. Influence of farm compost on soil quality and crop yields. Arch. Agron. Soil Sci. 58:S71-S75.

Eitzer, B. D. 1995. Emissions of volatile organic chemicals from municipal solid waste composting facilities. Environ. Sci. Technol. 29:896-902.

Hayes, E. T., T. P. Curran, and V. A. Dodd. 2006. Odour and ammonia emissions from intensive poultry units in Ireland. Bioresour. Technol. 97:933-939.

Hellebrand, H. J. 1998. Emission of nitrous oxide and other trace gases during composting of grass and green waste. J. Agric. Eng. Res. 69:365-375.

Krauss, P., T. Krauss, J. Mayer, and T. Wallenhorst. 1992. Untersuchung zur Entstehung und Verminderung von Gerüchen bei der Kompostierung. Staub. Reinhalt. Luft. 52:245-250.

Lewandowska, A. and L. Falkowska. 2004. Ammonia and ammonium over the southern Baltic Sea. Part 1. Preparation of aerosol and air samples for the determination of ammonia by the indophenol method. Oceanologia 46:175-184.

Kumar, A., C. P. Alaimo, R. Horowitz, F. M. Mitloehner, M. J. Kleeman, and P. G. Green. 2011. Volatile organic compound emissions from green waste composting: Characterization and ozone formation. Atmos. Environ. 45:1841-1848.

Radon, K., B. Danuser, M. Iversen, E. Monso, C. Weber, J. Hartung, K. J. Donham, U. Palmgren, and D. Nowak. 2002. Air contaminants in different European farming environments. Ann. Agric. Environ. Med. 9:41-48.

Smet, E., H. Van Langenhove, and I. De Bo. 1999. The emission of volatile compounds during the aerobic and the combined anaerobic/aerobic composting of biowaste. Atmos Environ. 33:1295-1303.

Tsai, C.-J., M.-L. Chen, A.-D. Ye, M.-S. Chou, S.-H. Shen, and I.F. Mao. 2008. The relationship of odor concentration and the critical components emitted from food waste composting plants. Atmos. Environ. 42:8246-8251.

Turan, N., A. Akdemir, and O. Ergun. 2007. Emission of volatile organic compounds during composting of poultry litter. Water Air Soil Pollut. 184:177-182.

Weatherburn, M. W. 1967. Phenol-hypochlorite reaction for determination of ammonia. Anal. Chem. 39:971-974.

Wells, A., K. Chan, and P. Cornish. 2000. Comparison of conventional and alternative vegetable farming systems on the properties of a yellow earth in New South Wales. Agric. Ecosyst. Environ. 80:47-60.

World Health Organization. 1989. Indoor Air Quality: Organic Pollutants. Report on a WHO Meeting, Berlin, 23-27 August 1987. EURO Reports and Studies 111 World Health Organization Regional Office for Europe, Copenhagen, Denmark. 